\title{
Vicinal Difunctionalization of Alkenes under Iodine(III) Catalysis involving Lewis-Base Adducts
}

\author{
Kristina Aertker, ${ }^{\mathrm{a}}$ Raquel J. Rama, ${ }^{\mathrm{a}}$ Julita Opalach $^{\mathrm{a}}$ and Kilian Muñiz ${ }^{\mathrm{a}, \mathrm{b} *}$ \\ a Institute for Chemical Research of Catalonia (ICIQ), The Barcelona Institute of Science and Technology, 16 Avgda. \\ Països Catalans, E-43007 Tarragona, Spain \\ Phone: +34977920 813; email: kmuniz@iciq.es \\ b ICREA, Pg. Lluís Companys 23, 08010 Barcelona, Spain
}

Supporting information for this article is available on the WWW under http://dx.doi.org/10.1002/adsc.201\#\#\#\#\#\#.

\begin{abstract}
The influence of a 2-pyridinyl substituent on the catalytic performance of aryliodide as a catalyst in iodine(III) chemistry was explored. An efficient Lews-base adduct between the pyridine nitrogen and the electrophilic iodine(III) center was identified and confirmed by X-ray analysis. This arrangement was shown to generate a kinetically competent superior catalyst structure for the catalytic dioxygenation of alkenes. It introduces the concept of Lewis-base adduct formation as a kinetic factor in iodine(I/III) catalysis.
\end{abstract}

Keywords: Alkenes; Catalysis; Iodine; Lewis Base; Oxidation

Hypervalent iodine(III) reagent $^{[1]}$ have been identified as versatile reagents for the difunctionalisation of alkenes. ${ }^{[2]}$ The general versatility of these oxidizing reagents in organic chemistry is further expressed by recent developments, which make use of their application in metal-free, environmentally benign oxidation catalysis. $^{[3]}$ In these cases, the iodine(III) state represents the active catalyst, which is continuously re-generated from a conventional iodine(I) precatalyst. In the prominent field of dioxygenation reactions of alkenes, ${ }^{[4,5]}$ the application of the standard hypervalent iodine reagent $\mathrm{PhI}(\mathrm{OAc})_{2} \quad \mathbf{1}$ for diacetoxylation is hampered by its notoriously low reactivity towards alkenes.

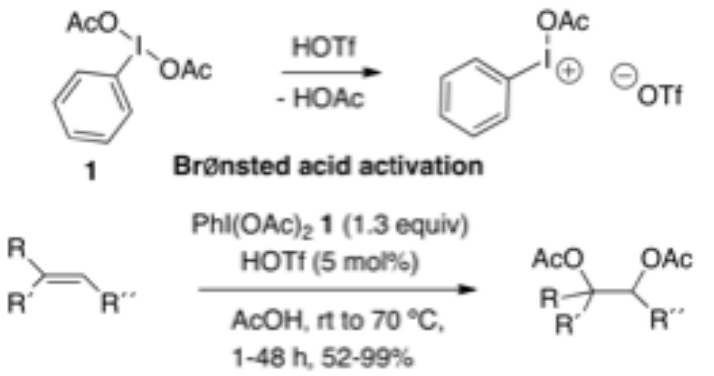

Scheme 1. Brønsted acid acceleration in the diacteoxylation of alkenes.
The desired reaction can be accelerated through addition of catalytic amounts of a strong Brønstedt acid, for example TfOH. In seminal work, Gade and Kang demonstrated that such acid catalysis significantly accelerates the alkene oxidation, presumably through protonolysis toward a cationic iodine center (Scheme 1). ${ }^{[6,7]}$ The latter displays enhanced electrophilicity and reactivity due to the free coordination site at iodine. The same observation was recently made in the development of an enantioselective catalytic diacetoxylation of styrenes, in which co-catalysis by $\mathrm{TfOH}$ was a crucial factor. ${ }^{[8]}$ Alternatively, activation of iodine(III) derivatives with the aid of fluorinated alcohols was discussed. ${ }^{[9]}$ It appears reasonable to investigate further structural diversification for the discrete formation of electrophilic iodine(III) catalyst states with free coordination sites. One approach in this direction should consist in the use of weakly coordinating Lewis bases.

The pyridine unit displays a long history of successful stabilization of electrophilic iodine centers. Barluenga's reagent $\left[\mathrm{I}(\mathrm{py})_{2}\right] \mathrm{BF}_{4}$ is certainly the most prominent example to this end, ${ }^{[10,11]}$ while pyridine coordination to electrophilic iodine(III) centers has been less investigated.

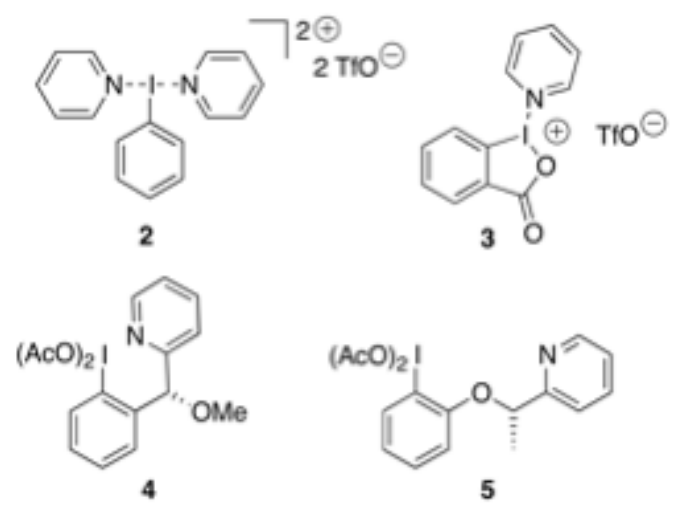


Figure 1. Pyridine coordination to iodine(III) in compounds $\mathbf{2}$ and $\mathbf{3}$, and chiral pyridinyl derivatives $\mathbf{4}$ and 5.

Examples in this area include the compound $\left[\mathrm{PhI}(\mathrm{py})_{2}\right](\mathrm{OTf})_{2} \quad$ (2), ${ }^{[12]}$ the corresponding benziodoxolone adduct $\mathbf{3}^{[13]}$ and the chiral derivatives 4 and 5, which were introduced by Wirth (Figure 1). ${ }^{[14,15]}$ Interestingly, the solid state structure of $\mathbf{4}$ does not display any interaction between the iodine(III) center and the nitrogen atom of the pyridinyl group. In agreement with this, the reported catalysis relied on co-activation by Brønsted acid. ${ }^{[15]}$ To probe the supportive context of pyridine coordination in an iodine(III) catalyst, the aryliodine 6 was synthesized from 2-phenyl pyridine ${ }^{[16,17]}$ and submitted to oxidation. Exploring several established oxidation agents, we observed that only peracetic acid provided an oxidation product (Scheme 2). With this particular oxidant, clean formation of the desired iodine(III) derivative 7 was observed.

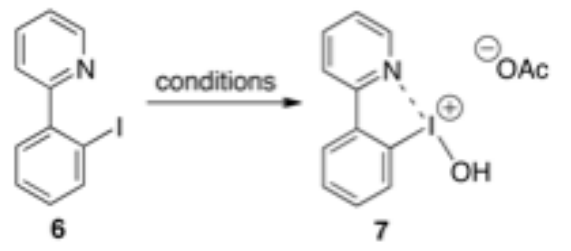

conditions:

Selectfluor (2.5 equiv).

$\mathrm{AcOH} / \mathrm{MeCN}(1 / 3), \mathrm{RT}, 6 \mathrm{~h} \quad$ n.r. [a]

$\mathrm{NaBO}_{3}-4 \mathrm{H}_{2} \mathrm{O}$ (15 equiv),

$\mathrm{AcOH}, 40^{\circ} \mathrm{C}, 12 \mathrm{~h}$

n.r.

$\mathrm{NalO}_{4}$ (1.03 equiv), NaOAc (2.2 equiv)

$\mathrm{AcOH} / \mathrm{Ac}_{2} \mathrm{O}(10 / 1), 118^{\circ} \mathrm{C}, 5 \mathrm{~h}$ n.r.

$\mathrm{AcO}_{2} \mathrm{H}$ (2.5 equiv),

$\mathrm{AcOH}, \mathrm{RT}, 15 \mathrm{~h}$

$92 \%[\mathrm{~b}]$

Scheme 2. Oxidation of iodine(I) compound $\mathbf{6}$ to iodine(III) compound 7. ${ }^{[\mathrm{a}]}$ n.r. $=$ no reaction. ${ }^{[\mathrm{b}]}$ isolated yield.

Suitable crystals of the new chelate 7 were grown from a solution in cyclohexane-dichloromethane solution. X-ray analysis confirmed the expected structure including the coordination of the pyridine group to the central iodine atom indicating the Lewis base assisted activation of the former iodine-acetoxy bond (Figure 2). ${ }^{[18]}$ The corresponding I-N bond length was determined to $2.443 \AA$, which is in good agreement to related bond distances of 2.44 to $2.46 \AA$ in related nitrogen coordination ${ }^{[17]}$ and of 2.24 to 3.13 $\AA$ in related derivatives of chelated iodine(III) complexes based on oxygen coordination. ${ }^{[19]}$ In general, intramolecular coordination of oxygen donor atoms to hypervalent iodine centers has been a common strategy, while related nitrogen donor coordination appears significantly less encountered.
The crystal structure determination also provides the corresponding iodoso benzene 8 (Figure 2), which undergoes intermolecular hydrogen bonding with 7. ${ }^{[18]}$ Iodoso derivative $\mathbf{8}$ originates from compound $\mathbf{7}$ upon loss of acetic acid (Scheme 3), presumably throughout the crystallization process. In an analogous manner, 7 can be restored from 8 by addition of acetic acid characterizing it as the acetic acid adduct of 7 .
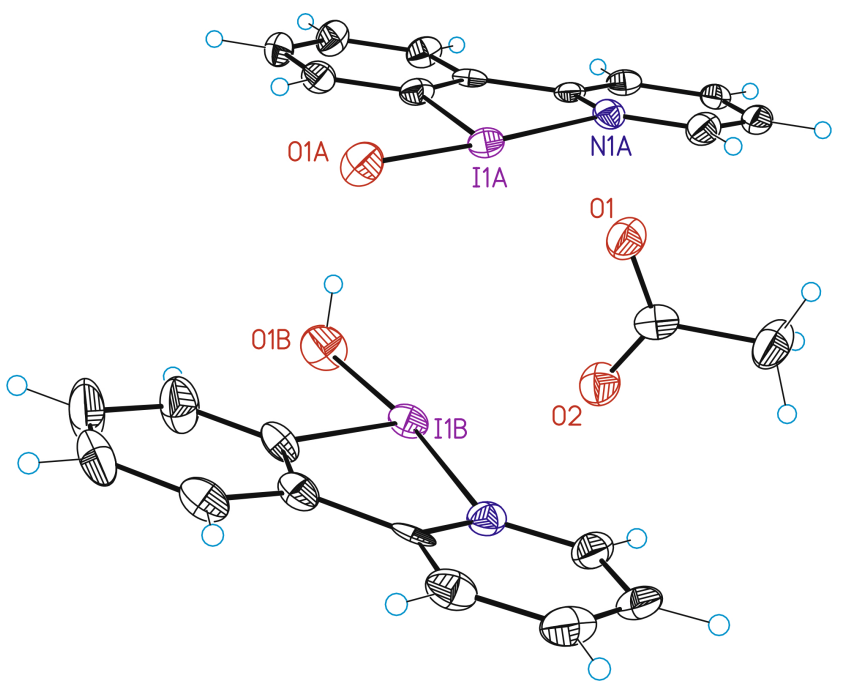

Figure 2. Solid-state structures of compounds 7 and 8 (ellipsoids at $50 \%$ probability). ${ }^{[18]}$ Selected bond lengths $[\AA]$ and angles $\left[{ }^{\circ}\right]$ : 7: I1A-O1A 1.921(5), I1A-N1A 2.443(6), I1A-O1 2.850(4), O1A-I1A-N1A167.2(2); 8: I1B-O1B 1.946(5), I1B-N1B 2.406(6), O1B-I1B-N1B 167.2(2).

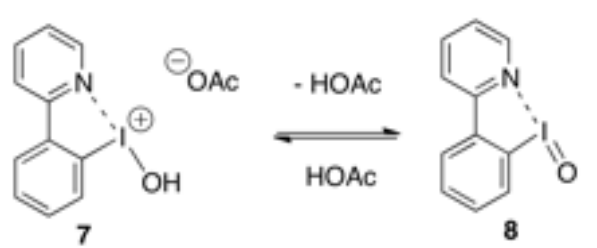

Scheme 3. Relation between iodine(III) compounds 7 and 8.

Subsequent work addressed the diacetoxylation of alkenes with compound $\mathbf{6}$ as catalyst. Given the effective oxidation of $\mathbf{6}$ to 7, we decided to employ peracetic acid as the terminal oxidant and to follow conditions established previously for the diacetoxylation of alkenes. ${ }^{[20]}$

A number of different alkenes were submitted to diacetoxylation (Scheme 4), leading to chemoselective oxidation of the $\mathrm{C}-\mathrm{C}$ double bonds in all cases. As commonly observed, ${ }^{[5,6,8,20]}$ styrenes represent the preferred substrate class in this reaction, and products 10a-10h could be obtained in 66-92\% isolated yields. The same was observed for product 10i, which gave clean diacetoxylation without any potentially competing rearrangement or allylic 
oxidation. From observation of the crude reaction mixture of $\mathbf{1 0 d}$, it was concluded that these reactions proceed through initial formation of the 1-hydroxy-2acetoxy derivative, which derives from the Woodward pathway. ${ }^{[21]}$ They are converted into uniform vicinal diacetoxy products upon treatment with acetic anhydride. In contrast, $(E)$ - and $(Z)-\beta$ methyl styrene and (E)-O-acetoxy cinnamic ester yield the corresponding products $\mathbf{1 0 j - 1 0 l}$ as diastereomeric mixtures due to competing Woodward and Prevost ${ }^{[22]}$ pathways.

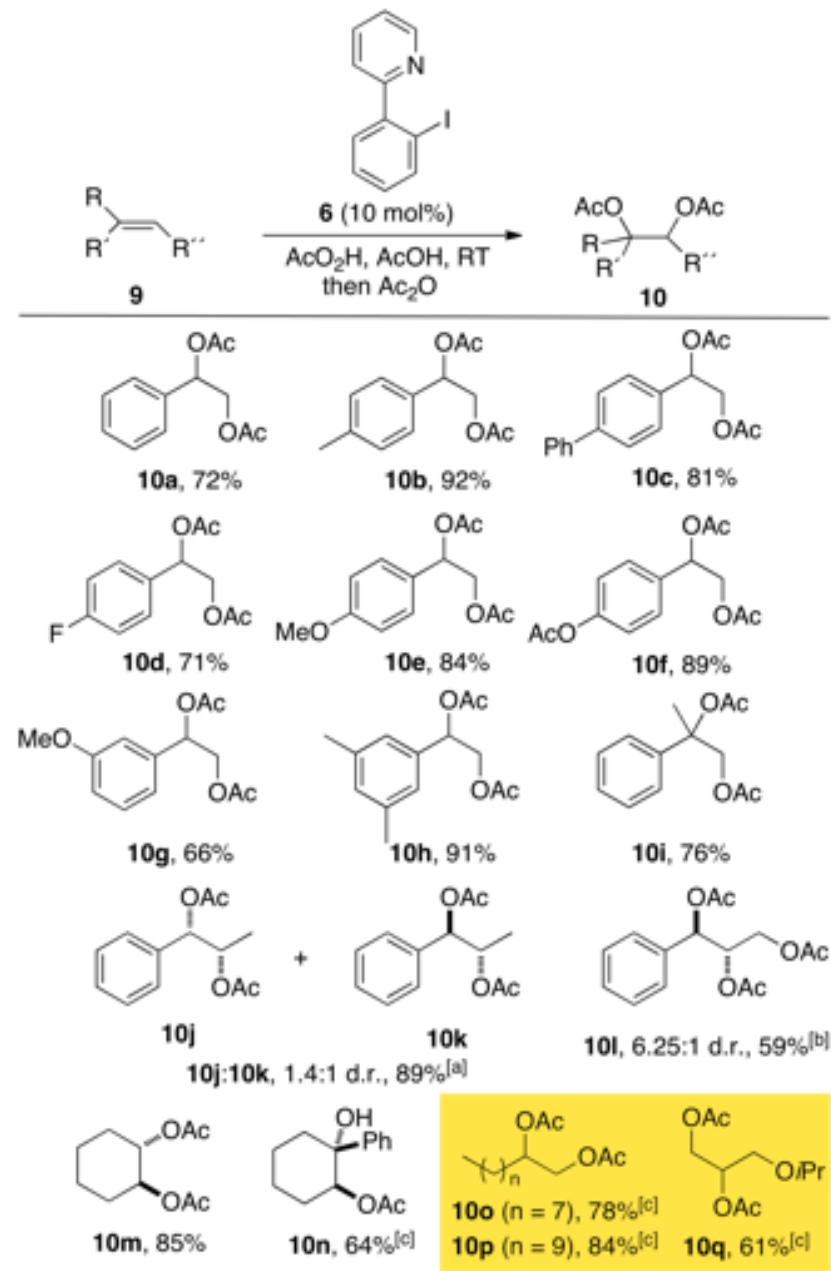

Scheme 4. Catalytic diacetoxylation of alkenes. Given yields refer to isolated material after purification. ${ }^{[\mathrm{a}]}$ From reaction with $(E)$ - $\beta$-methyl styrene $\mathbf{9 j}$. ${ }^{[\mathrm{b}]}$ From reaction with (E)-O-acetoxy cinnamic alcohol 91. [c] Without treatment with acetic anhydride.

Cyclic aliphatic alkenes can also be employed as demonstrated for formation of products $\mathbf{1 0 m}, \mathbf{n} .^{[6,20]}$ Finally, linear aliphatic alkenes give direct rise to the diacetoxylated products $\mathbf{1 0 0}-\mathbf{q}$ without required treatment with acetic anhydride, which indicates a Prevost pathway ${ }^{[22]}$ to be operative.

The beneficial effect of the 2-pyridinyl group was demonstrated within a kinetic competition experiment between catalyst $\mathbf{6}$ and iodobenzene 1 . Monitoring by ${ }^{19} \mathrm{~F}$ NMR the progress of oxidation of 4-fluorostyrene 9d in acetic acid- $\mathrm{d}_{4}$ as solvent, a clear acceleration of the reaction was found to result from the presence of the coordinating pyridine group (Figure 3). Comparison of the initial rates indicate that 6 outperforms 1 by a factor of over 2. This kinetic data clearly demonstrates that the concept of Lewis-base coordination can accelerate hypervalent iodine catalysis to a significant extent.

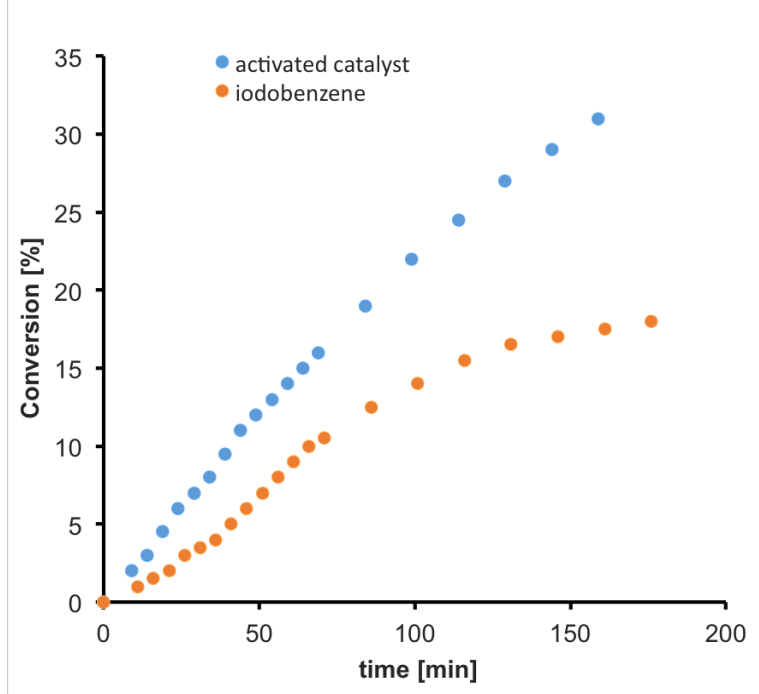

Figure 3. Initial kinetic profiles for the dioxygenation of 4fluorostyrene 9d with catalyst $\mathbf{6}$ and iodobenzene 1, respectively.

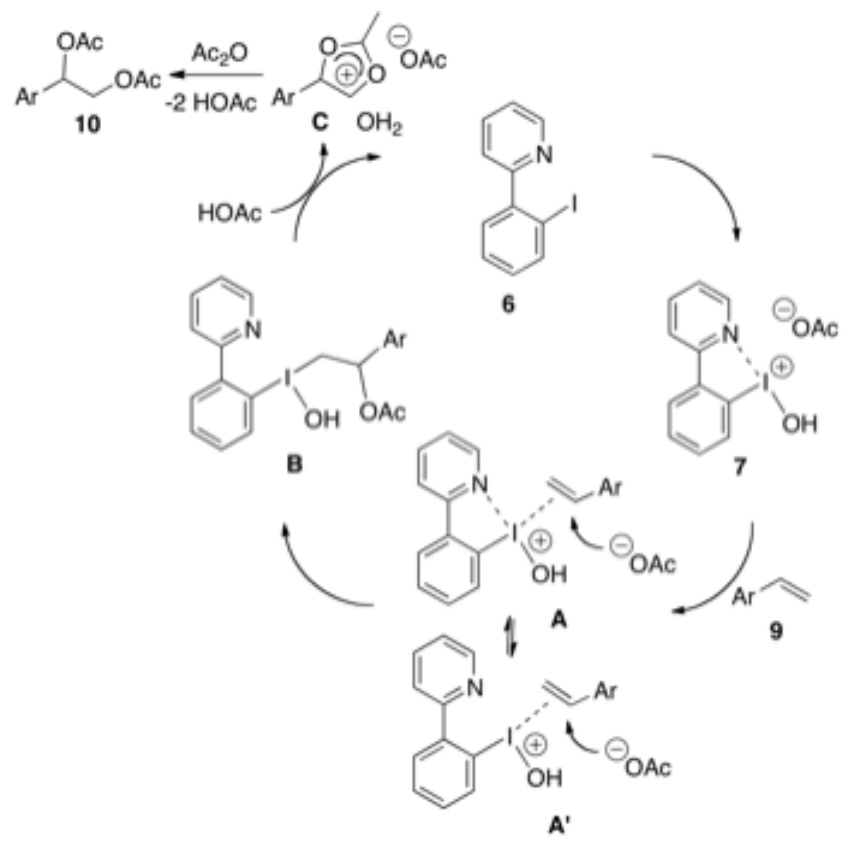

Figure 4. Catalytic cycle for the catalytic diacetoxylation of styrenes 9.

The proposed catalytic cycle (Figure 4) comprises the documented oxidation of catalyst 6 to 7 with the iodine(III) catalyst state. Coordination of alkene 9 to 
the electrophilic iodine center in 7 may involve an associative process through $\mathbf{A}$ or directly arrive at A' with three-coordinate iodine center. Subsequent nucleoacetoxylation initiates the difunctionalization via $\mathbf{B}$, from which catalyst $\mathbf{6}$ is regenerated via reductive oxygenation (As discussed, for styrenes 9a$\mathbf{h}$, this step should consist of a Woodward pathway).

In summary, we have reported a new catalyst for the iodine(III) catalyzed dioxygenation of alkenes. The kinetic competence of this catalyst relies on an efficient Lewis-base coordination of a pyridine group to the electrophilic iodine(III) catalyst. This concept should provide space for new catalyst design in the field of hypervalent iodine catalysis.

\section{Experimental Section}

Synthesis of catalyst $6 .^{[17]} 2$-(2-bromophenyl) pyridine (162 $\mathrm{mg}, 0.7 \mathrm{mmol})$ was dissolved in absolute THF $(5.5$ $\mathrm{mL})$, cooled to $-78^{\circ} \mathrm{C}$ and $n \mathrm{BuLi}(0.38 \mathrm{~mL}, 2 \mathrm{M}$ in hexane, $0.76 \mathrm{mmol}, 1.1$ equiv.) was added. The reaction was stirred at $-78{ }^{\circ} \mathrm{C}$ for $2 \mathrm{~h}$. An iodine solution $(3 \mathrm{~mL}, 1 \mathrm{M}$ in THF, $3.01 \mathrm{mmol}, 4.3$ equiv.) was then added at $-78{ }^{\circ} \mathrm{C}$. The reaction was warmed to r.t., stirred for 20 hours and evaporated to dryness. Column chromatography $\left(\mathrm{SiO}_{2}, 10 \%\right.$ ethyl acetate/hexane/EtOAc, 90/10, v/v) provided the title compound 6 as a white solid $(106.8 \mathrm{mg}, 54 \%)$.

General Procedure for Diacetoxylation. A Pyrex tube equipped with a stirrer bar was charged with iodine(I) catalyst $6(5.62 \mathrm{mg}, 0.02 \mathrm{mmol}, 10 \mathrm{~mol} \%)$ and $\mathrm{AcOH}(1$ $\mathrm{mL})$. AcOOH (36\% in $\mathrm{AcOH}, 90 \mu \mathrm{L}, 0.44 \mathrm{mmol}, 2.2$ eq.) was added and the reaction mixture was stirred at room temperature for $1 \mathrm{~h}$. Then the respective alkene $(0.2 \mathrm{mmol}$, 1.0 eq.) was added and the reaction mixture was stirred at room temperature for further $18 \mathrm{~h} . \mathrm{H}_{2} \mathrm{O}(2 \mathrm{~mL})$, brine $(1.5$ $\mathrm{mL}$ ) and $\mathrm{CH}_{2} \mathrm{Cl}_{2}$ were added and the aqueous layer was extracted twice with $\mathrm{CH}_{2} \mathrm{Cl}_{2}$. The combined organic phases were dried over $\mathrm{Na}_{2} \mathrm{SO}_{4}$ and concentrated under reduce pressure. Compounds 10n-q were directly purified by flash column chromatography on silica gel to provide analytically pure products. For compounds 10a-m, the crude product was dissolved in $\mathrm{CH}_{2} \mathrm{Cl}_{2}(0.5 \mathrm{~mL})$ and acetic anhydride $(55 \mu \mathrm{L}, 0.5 \mathrm{mmol}, 2.5$ eq.), pyridine $(40 \mu \mathrm{L}, 0.5$ mmol, 2.5 eq.) and DMAP (6.1 mg, $0.05 \mathrm{mmol}, 0.25$ eq.) were added. After stirring at room temperature for $5 \mathrm{~h}$, the reaction was quenched with aqueous $\mathrm{HCl}(6 \mathrm{M}, 3 \mathrm{~mL})$ and EtOAc $(3 \mathrm{~mL})$. The aqueous phase was extracted twice with EtOAc and the combined organic layers were dried over $\mathrm{Na}_{2} \mathrm{SO}_{4}$, and concentrated under reduced pressure. The crude product was purified by flash column chromatography on silica gel to provide analytically pure products.

\section{Acknowledgements}

The authors thank the Spanish Ministry for Economy and Competitiveness and FEDER (CTQ2014-56474R grant to K. M., Severo Ochoa Excellence Accreditation 2014-2018 to ICIQ, SEV2013-0319) and the CERCA Programme/Government of Catalonia for financial support and Dr. E. Escudero-Adán for the $X$-ray analysis. $K A$ is an undergraduate student from $L M U$ Munich.

\section{References}

[1] a) V. V. Zhdankin, V. V. Hypervalent Iodine Chemistry Preparation, Structure and Synthetic Applications of
Polyvalent Iodine Compounds, Wiley, Chichester 2013; b) Iodine Chemistry and Applications (Ed.: T. Kaiho), Wiley, New Jersey 2015; c) Top. Curr. Chem. 2003, Vol. 224 (Ed.: T. Wirth), Springer, Berlin; d) Top. Curr. Chem. 2016, Vol. 373 (Ed.: T. Wirth), Springer, Berlin; e) A. Yoshimura, V. V. Zhdankin, Chem. Rev. 2016, $116,3328$.

[2] a) R. M. Romero, T. H. Wöste, K. Muñiz, Chem. Asian J. 2014, 9, 972; b) M. Uyanik, K. Ishihara, J. Synth. Org. Chem. Jpn. 2012, 70, 1116; c) Singh, F. V.; Wirth, T. Chem. Asian J. 2014, 9, 950; d) F. Berthiol, Synthesis 2015, 47, 587.

[3] a) R. D. Richardson, T. Wirth, Angew. Chem. Int. Ed. 2006, 45, 4402; b) M. Ochiai, K. Miyamoto, Eur. J. Org. Chem. 2008, 4229; c) M. Ochiai, Chem. Rec. 2007, 7, 12; d) T. Dohi, Y. Kita, Chem. Commun. 2009, 2073; e) M. Uyanik, K. Ishihara, Chem. Commun. 2009, 2086.

[4] For initial dioxygeation reactions: a) U. H. Hirt, B. Spingler, T. Wirth, J. Org. Chem. 1998, 63, 7674; b) T. Wirth, U. H. Hirt, Tetrahedron: Asymmetry 1997, 8, 23; c) U. H. Hirt, M. F. H. Schuster, A. N. French, O. G. Wiest, T. Wirth, Eur. J. Org. Chem. 2001, 1569; d) A. C. Boye, D. Meyer, C. K. Ingison, A. N. French, T. Wirth, Org. Lett. 2003, 5, 2157.

[5] For recent catalytic dioxygenation reactions: a) M. Fujita, K. Mori, M. Shimogaki, T. Sugimura, Org. Lett. 2012, 14, 1294; b) M. Fujita, K. Mori, M. Shimogaki, T. Sugimura, $R S C A d v$. 2013, 3, 17717; c) M. Shimogaki, M. Fujita, T. Sugimura, Eur. J. Org. Chem. 2013, 7128.

[6] Y.-B. Kang, L. H. Gade, J. Am. Chem. Soc. 2011, 133, 3658.

[7] For Lewis acid activation: a) M. Fujita, M. Wakita, T. Sugimura, Chem. Commun. 2011, 47, 3983; b) W. Zhong, J. Yang, X. Meng, Z. Li, J. Org. Chem. 2011, 76, 9997.

[8] a) S. Haubenreisser, T. H. Wöste, C. Martínez, K. Ishihara, K. Muñiz, Angew. Chem. Int. Ed. 2016, 55, 413; b) T. H. Wöste, K. Muñiz, Synthesis 2016, 48, 816.

[9] I. Colomer, C. Batchelor-McAuley, B. Odell, T. J. Donohoe, R. G. Compton, J. Am. Chem. Soc. 2016, 138,8855 .

[10] a) J. Barluenga, J. M. González, P. J. Campos, G. Asensio, Angew. Chem. Int. Ed. 1985, 24, 319; b) J. Barluenga, Pure Appl. Chem. 1999, 71, 431; c) M. Justin, L. Amber, G. Benjamin, Org. Synth. 2010, 87, 28; recent examples: d) J. Barluenga, E. CamposGómez, A. Minatti, D. Rodríguez, J. M. González, Chem. Eur. J. 2009, 15, 8946; e) J. Barluenga, H. Vázquez-Villa, I. Merino, A. Ballesteros, J. M. González, Chem. Eur. J. 2006, 12, 5790; f) J. Barluenga, H. Vázquez-Villa, A. Ballesteros, J. M. González, Adv. Synth. Catal. 2005, 347, 526; g) J. Barluenga, M. Trincado, M. Marco-Arias, A. Ballesteros, E. Rubio, J. M. González, Chem. Commun. 2005, 2008; h) J. Barluenga, M. Trincado, E. Rubio, J. M. González, Angew. Chem. Int. Ed. 2006, 45, 3140. 
[11] For structural studies: a) C. Álvarez-Rúa, S. GarcíaGranda, A. Ballesteros, F. González-Bobes, J. M. González, Acta Cryst. 2002, E58, o1381; b) A. C. C. Carlsson, K. Mehmeti, M. Uhrbom, A. Karim, M. Bedin, R. Puttreddy, R. Kleinmeier, A. A. Neverov, B. Nekoueishahraki, J. Grafensetin, K. Rissanen, M. Erdelyi, J. Am. Chem. Soc. 2016, 138, 9853; c) M. Bedin, A. Karim, M. Reitti, A.-C. C. Carlsson, F. Tepic, M. Cetina, F. Pan, V. Havel, F. Al-Ameri, V. Sindelar, K. Rissanen, J. Gräfenstein, M. Erdélyi, Chem. Sci. 2015, 6, 3746; d) Y. Kim, E. J. Mckinley, K. E. Christensen, N. H. Rees, A. L. Thompson, Cryst. Growth Des. 2014, 14, 6294; e) T. Okitsu, S. Yumitate, K. Sato, Y. In, A. Wada, Chem. Eur. J. 2013, 19, 4992.

[12] R. Weiß, J. Seubert, Angew. Chem. int. Ed. 1994, 33, 891.

[13] V. V. Zhdankin, A. Y. Koposov, N. V. Yashin, Tetrahedron Lett. 2002, 43, 5735.

[14] P. Mizar, A. Laverny, M. El-Sherbini, U. Farid, M. Brown, F. Malmedy, T. Wirth, Chem. Eur. J. 2014, 20, 9910.

[15] F. Malmedy, T. Wirth, Chem. Eur. J. 2016, 22, 16072-16077.

[16] See Supporting Information for details.

[17] K. Niedermann, J. M. Welch, R. Koller, J. Cvengros, N. Santchi, P. Battaglia, A. Togni, Tetrahedron 2010, $66,5753$.

[18] X-ray crystallographic data for compound $\mathbf{5 / 6}$ have been deposited with the Cambridge Crystallographic Data Centre database (http://www.ccdc.cam.ac.uk/) under code CCDC 1507745.

[19] A. Yoshimura, M. S. Yusubov, V. V. Zhdankin, Org. Biomol. Chem. 2016, 14, 4771.

[20] Y.-B. Kang, L. H. Gade, J. Org. Chem. 2012, 77, 1610.

[21] R. B. Woodward, F. V. Brutcher, Jr., J. Am. Chem. Soc. 1958, 80, 209.

[22] C. Prévost, Compt. Rend. 1933, 196, 1129. 


\section{COMMUNICATION}

Vicinal Difunctionalization of Alkenes under Iodine(III) Catalysis involving Lewis-Base Adducts

Adv. Synth. Catal. Year, Volume, Page - Page
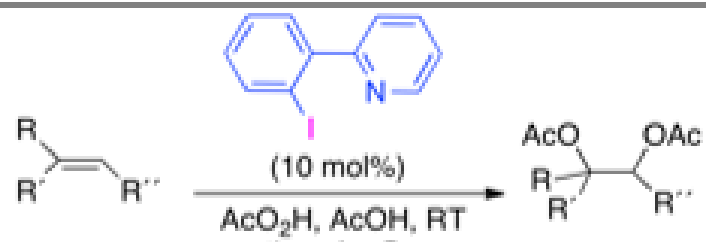

Kristina Aertker, Raquel J. Rama, Julita Opalach and Kilian Muñiz*

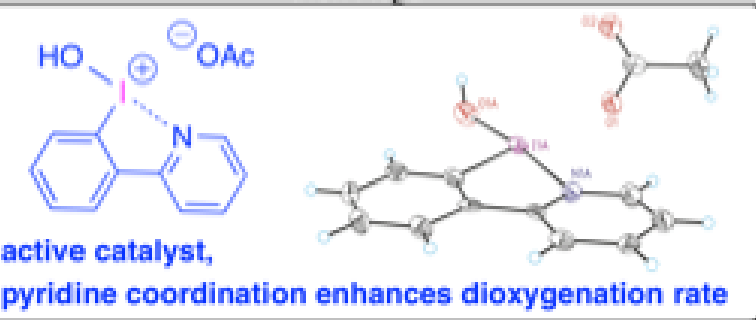

